\title{
Problems of "Buffon type" for polygonal strips
}

\author{
Andrei Duma and Marius Stoka
}

\begin{abstract}
Andrei Duma promovierte 1972 und habilitierte sich 1975 an der LMU München. Nach einer Dozentur in Regensburg und einer Professur in Bochum ist er seit 1981 Professor für Komplexe Analysis an der Fernuniversität Hagen. Seine Hauptforschungsgebiete sind die Riemannschen Flächen, die Teichmüller-Theorie und die stochastische Geometrie.

Marius Stoka promovierte 1961 in Bukarest. Nach Professuren in Bukarest, Montpellier und Toulouse ist er seit 1976 Ordinarius für Geometrie in Turin. Seine Hauptforschungsgebiete sind die Differential- und die stochastische Geometrie sowie die Wahrscheinlichkeitstheorie und die Statistik.
\end{abstract}

Let us consider, in the Euclidean plane $E_{2}$, a polygonal line formed by segments of length $b$ and $c$, making an angle of amplitude $\pi-(\beta+\gamma)=\pi-\vartheta$. Using this line, we construct a lattice $\mathscr{R}$, as shown in Fig. 1.

It is not restrictive to agree that, for example, $\beta \leq \gamma$ and hence $b \geq c$. Clearly we have $b \sin \beta=c \sin \gamma$.

We want to determine the probability that a random segment of constant length $l$, uniformly distributed in a bounded region of the plane, intersects one of the lines of the lattice $\mathscr{R}$.

The following result extends the classical Buffon's needle problem.

Das Nadelproblem von Buffon ist eines der ältesten Probleme der geometrischen Wahrscheinlichkeitstheorie. Es wird nach der Wahrscheinlichkeit gefragt, dass eine auf ein vorgelegtes, gleichmässig liniertes Papier fallengelassene Nadel eine der Linien trifft. Es gibt eine Fülle von Arbeiten, die das klassische Problem von Buffon verallgemeinern. Die Autoren haben in einigen Arbeiten Gitter betrachtet, deren Fundamentalzellen nicht-konvexe Polygone sind. An dieser Stelle wird ein unendlich langes Band betrachtet, das durch Translationen die Ebene überdeckt. Die Fundamentalzelle ist diesmal die Vereinigung zweier Parallelogramme mit einer gemeinsamen Seite, die nicht zum Rand gehört. Als Spezialfall erhält man das klassische Ergebnis von Buffon. 


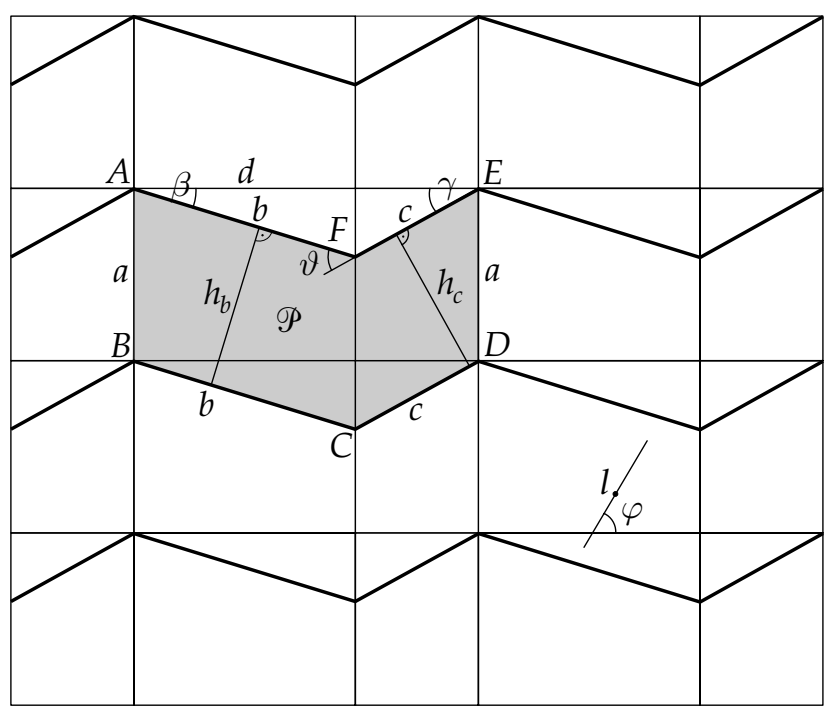

Fig. 1

Theorem. If $l<\min \left(b, c, d, h_{b}, h_{c}\right)$, the probability that a segment s of length $l$ intersects one of the lines of the lattice $\mathscr{R}$ is:

$$
p=\frac{l}{2 \pi a d}\left[4(b+c)-\left(1-\frac{\vartheta}{\tan \vartheta}\right) l\right]
$$

Proof. Let $\mathscr{P}$ be the polygon constructed by using a pair of segments of lengths $b$ and $c$ as shown in Fig. 1. We denote by $M$ the set of segments $s$ of length $l$ whose midpoint is inside the polygon $\mathscr{P}$ and by $\mathcal{N}$ the set of segments $s$ having the midpoint within $\mathscr{P}$ and intersecting one of the lines of the lattice $\mathscr{R}$. Hence the probability we are looking for can be written as:

$$
p=\frac{\mu(\mathcal{N})}{\mu(\mathcal{M})}
$$

where $\mu$ is the Lebesgue measure.

The measures $\mu(\mathcal{N})$ and $\mu(\mathcal{M})$ will be computed by means of the elementary kinematic measure in the Euclidean plane [1, p. 126]

$$
d K=d x \wedge d y \wedge d \varphi
$$

where $x$ and $y$ are the coordinates of the midpoint of the segment $s$ and $\varphi$ is an angle of rotation.

Since $\operatorname{area}(\mathscr{P})=a(b \cos \beta+c \cos \gamma)$, we immediately find:

$$
\mu(\mathcal{M})=\int_{0}^{\pi} d \varphi \iint_{\{(x, y) \in \mathscr{P}\}} d x d y=\pi a(b \cos \beta+c \cos \gamma) .
$$


Let now $\Delta$ be an axis making an angle $\beta$ with a segment of length $b$ of the polygon $\mathscr{P}$, and consequently an angle $\gamma$ with a segment of length $c$ in the same polygon.

We denote by $\mathscr{F}(\varphi) \subset \mathscr{P}$ the family of all the midpoints of the segments $s$ of length $l$ forming an angle $\varphi$ with the axis $\Delta$ and intersecting one of the lines of the lattice $\mathscr{R}$. Thus we get

$$
\mu(\mathcal{N})=\int_{0}^{\pi} d \varphi \iint_{\{(x, y) \in \mathscr{F}(\varphi)\}} d x d y=\int_{0}^{\pi}[\operatorname{area}(\mathscr{F}(\varphi))] d \varphi .
$$

We notice that $\mathscr{F}(\varphi)$ has two connected components with the same area. Hence, in order to compute area $[\mathscr{F}(\varphi)]$ it suffices to consider only one of the two components. In order to do this, we have to distinguish three cases:

1. $0<\varphi \leq \gamma$;

2. $\gamma<\varphi \leq \pi-\beta$;

3. $\pi-\beta<\varphi \leq \pi$.

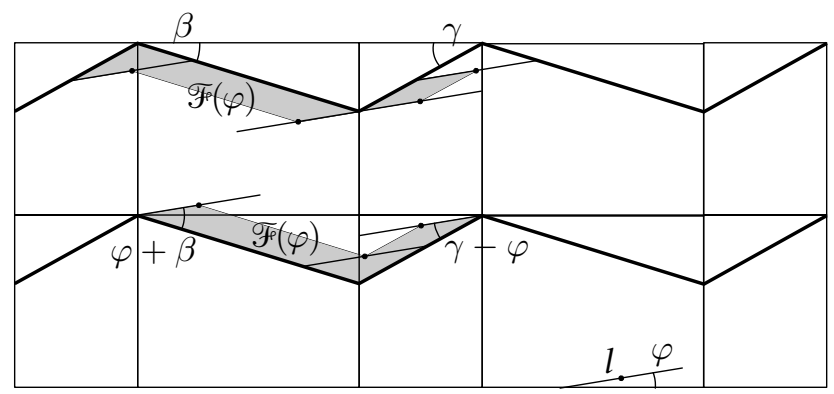

Fig. 2

If $0<\varphi \leq \gamma$, we have (see Fig. 2)

$$
\operatorname{area}[\mathscr{F}(\varphi)]=b l \sin (\beta+\varphi)+c l \sin (\gamma-\varphi)-\frac{l^{2} \sin (\gamma-\varphi) \sin (\beta+\varphi)}{\sin \vartheta},
$$

and therefore

$$
\int_{0}^{\gamma}[\operatorname{area}(\mathscr{F}(\varphi))] d \varphi=b l[\cos \beta-\cos \vartheta]+c l(1-\cos \gamma)+\frac{l^{2}}{2 \sin \vartheta}[\gamma \cos \vartheta-\cos \beta \sin \gamma] .
$$

If $\gamma<\varphi \leq \pi-\beta$, we have (see Fig. 3)

$$
\operatorname{area}[\mathscr{F}(\varphi)]=b l \sin (\varphi+\beta)+c l \sin (\varphi-\gamma),
$$

and thus

$$
\int_{\gamma}^{\pi-\beta}[\operatorname{area}(\mathscr{F}(\varphi))] d \varphi=(b+c)(1+\cos \vartheta) l .
$$




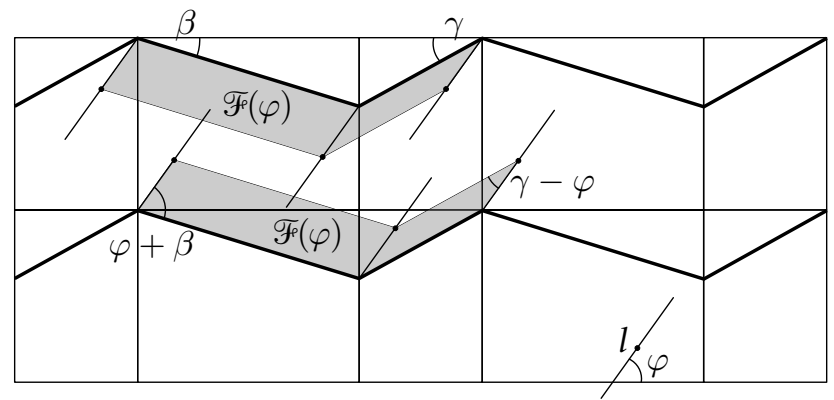

Fig. 3

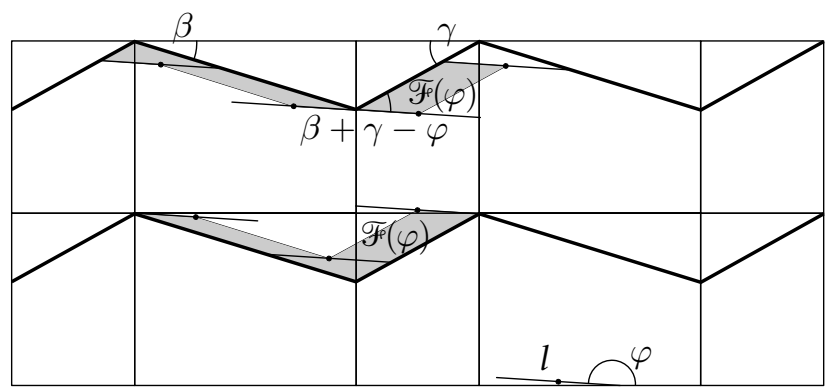

Fig. 4

Lastly, if $\pi-\beta<\varphi \leq \pi$, we have (see Fig. 4)

$$
\operatorname{area}[\mathscr{F}(\varphi)]=-b l \sin (\beta+\varphi)+c l \sin (\varphi-\gamma)+\frac{l^{2} \sin (\varphi-\gamma) \sin (\beta+\varphi)}{\sin \vartheta},
$$

and hence

$\int_{\pi-\beta}^{\pi}[\operatorname{area}(\mathscr{F}(\varphi))] d \varphi=b l(1-\cos \beta)+c l(\cos \gamma-\cos \vartheta)+\frac{l^{2}}{2 \sin \vartheta}(\beta \cos \vartheta-\sin \beta \cos \gamma)$.

Formulas (5), (6) and (7) give

$$
\int_{0}^{\pi}[\operatorname{area}(\mathscr{F}(\varphi))] d \varphi=2(b+c) l-\left(1-\frac{\vartheta}{\tan \vartheta}\right) \frac{l^{2}}{2},
$$

that is, recalling formula (4)

$$
\mu(\mathcal{N})=2(b+c) l-\left[1-\frac{\beta+\gamma}{\tan (\beta+\gamma)}\right] \frac{l^{2}}{2}=2(b+c) l-\left[1-\frac{\vartheta}{\tan (\vartheta)}\right] \frac{l^{2}}{2} .
$$

By replacing (3) and (8) in (2) we obtain the stated probability (1). 
Remark. When $b=c$, we have $\beta=\gamma$ and the probability (1) becomes:

$$
p=\frac{2 l}{\pi a \cos \beta}-\frac{l^{2}}{4 \pi a b \cos \beta}\left(1-\frac{2 \beta}{\tan 2 \beta}\right) .
$$

Letting $\beta \rightarrow 0$ in the above probability, we get Buffon's result

$$
p=\frac{2 l}{\pi a}
$$

\section{References}

[1] Poincaré, H.: Calcul des probabilités, ed. 2, Carré, Paris, 1912.

\section{Andrei Duma}

FB Mathematik

Fernuniversität-GSH

Lützowstr. 125

D-58084 Hagen, Germany

Marius Stoka

Dipartimento di Matematica

Università di Torino

via Carlo Alberto, 10

I-10123 Torino, Italy 